\title{
English Phonemic Awareness of Students with Visual Disabilities
}

\author{
Aghnessia Kusumaning Arum ${ }^{1}$, Alies Poetri Lintangsari ${ }^{{ }^{*}}$, Widya Caterine Perdhani ${ }^{1}$ \\ ${ }^{1}$ Faculty of Cultural Studies, Universitas Brawijaya, Indonesia, Indonesia
}

\begin{abstract}
Most of researches have reported the significance of English phonemic awareness to the success of learning English, but less discussions involving students with visual disabilities. Students with visual disabilities lacks of visual input and form a strong sensitivity to audio input, researches have reported that this condition affect their spelling ability, yet, their ability in recognizing English phonemes has been less explored especially in Indonesia. Thus, this research aims to describe the phonemic awareness of students with visual disabilities who learn English as Foreign Language. The participants of this research are students with visual disabilities whether active or passive braille user. 7 students with visual disabilities participated in an Online English Phonemic Awareness Test. Two independent raters rated the data independently. Interrater agreement was applied to ensure the objectivity of two independent interrater. The findings show that students with visual disabilities are aware to consonants Fricative alveolar, Plosive bilabial, and Plosive alveolar sounds but struggling with Fricative velar and Affricative velar sound, they are also aware of vowels Close mid front vowel, Close front long vowel sounds, Close mid back vowel and Open central vowel but struggling in identifying Open back vowel, Close mid central vowel, and Open mid back vowel. English phonemic awareness is a very important basic thing in language learning. However, it will be very challenging for ESL learners, especially those who learn are blind students because of certain obstacles that blind students have so that strategies are needed in language learning.

Keywords: Phonemic, Blind Student Awareness, Braille Reader, English Language Learning
\end{abstract}

\section{Research Background}

Blindness is a condition of having severely impaired or absolutely no sense of sight. Children who are blind are poor focusing or trouble following objects and have an inability to see objects at a distance. Blindness affects the development of language; it is one area minimally affected by the lack of vision. Research reported that the language development of blind children is difficult and delayed (Perez, n.d.), Blind children will not have the same opportunity to casually observe and make contact with signs and materials in their environment in a relaxed manner. Blind children need a lot of direct experience with real objects in the form of descriptions of hearing and literacy environments. Blind student sometimes has obstacles in terms of describing something 
when learning new things. Blind students during language learning may have their own difficulties for example they cannot figure out the details of the words they hear so that there may be mistakes when they spell out the sound structure of the word.

The blind student in (Dodd \& Conn, 2000) study show partial or uneven progression in the development of phonological awareness skills. Therefore, further research is needed to see the development of phonological awareness skills of children with visual impairments and to improve understanding of the relationship between phonological awareness and reading ability. (Gillon \& Young, n.d.) (Kuo \& Anderson, 2006) state that phonological awareness describes the ability to reflect and manipulate phonological units in a language, and there is a need for sensitivity to understand the phonological structure of a language. It plays a role as it is described the ability to break down spoken words into its smallest segment. Phonological awareness is a general competency that children need to master reading regardless of the linguistic nature of the language being studied (Lafrance \& Gottardo, 2005). The development of phonological awareness in children with visual disabilities is similar to children who aren't (Gillon \& Young, n.d.). (Dodd \& Conn, 2000) concluded that the logographic nature of braille can affect the reader's ability to group words phonetically. (Dodd \& Conn, 2000) found that students who used non-abbreviated braille had similar phonological or phonemic awareness skills to their seeing peers. Moreover, children with visual disabilities performed well on phonological awareness tasks that developed early, such as rhyme production and breaking syllables, and demonstrated developed knowledge at the phoneme level. (Stahl \& Murray, n.d.), with the exception, blind children have difficulty in recognizing rhyme, other than that they can show good abilities.

Research on children with awareness has shown that there is a development of consciousness in the phonological segment of the largest and most common units such as words and syllables to the smallest and most complex units such as phonemes (Mott \& Rutherford, 2012). Students who are braille readers usually have more sensitivity to sound but there could be an incorrect spelling of some words if they don't read the word. Previous studies found a strong association in phonological awareness and accuracy in reading and understanding braille (Gillon \& Young, n.d.). Then, another study suggested that the association between the level of phonological awareness and the initial stage of spelling ability was consistent (Melby-Lervåg et al., 2012). Intriguingly, researches that involves sighed children also finds there were no statistical differences between students with visual disabilities and the standardized sight assessment samples for the fields of non-word spelling, spoonerism, and fluent rhyme (Mott \& Rutherford, 2012). In drawing conclusions about the development of phonological awareness skills by braille readers, the contradiction of these two studies is still insufficient. 
Blind students who are braille readers and have no additional disabilities have better phonological awareness than print readers. Previous research appreciated that accurate spelling was because braille would help them conceptualize and the spelling had a social and emotional dimension. They felt that correct spelling could be used as a means of feeling safe and accepted in the school and community environment. Spelling is also used as a measure of one's educational level (Jones \& Macken, 1995). (Hill et al., n.d.) stated that reading braille requires a high level of phonological awareness, while (Stahl \& Murray, n.d.) stated that students who read braille, make more use of the information from the whole word rather than the information made by letters. It indicates that the ability of braille readers can be improved, not only about sound but it will focus more on the phonology that helps blind students pronounce words correctly or incorrectly.

Aforementioned researches have comprehensively reported the phonological awareness of English Native whether they are Blinds or sighted students, but less research has reported the English phonemic awareness of Indonesian EFL Learners. It is stated by (Snyder \& Kesselman, 1972) that in the second language (L2) classroom, especially spelling is often challenging for the visually impaired. The study of (Lailiyah et al., 2020) found that students with visual impairments who do not use braille in the target language have a harder time writing because they are less exposed to the formation of words that can lead to spelling errors. Moreover, (Rokhman et al., 2020) reported that there are differences in the characteristics of English and Indonesian phonemes that can cause problems for students in the process of understanding phonemic awareness. Since the participants in this study were EFL learners, (Collins et al., 2019) stated that students who are non-native speakers are struggling because there is always a difference between the phonemes of one language and another.

(Zhao et al., 2017) study stated that the crucial role of metalinguistic awareness and phonological awareness as one of its subsets in acquiring English Spelling both for native speakers and foreign speakers in English. Despite the significance of English Phonemic Awareness toward EFL learning, less researches reported the English Phonemic Awareness of Indonesian EFL Learners especially those with visual disabilities, whereas, English Teaching Practices should welcome all learners with diverse needs including those with visual disabilities. Thus, the aims of this research are to describe the phonological awareness skills of student with visual disabilities.

\subsection{English Phoneme and Syllable}

English Phoneme consist of two types of sounds, consonants and vowels. Consonant is the sound in which the flow of air encounters resistance in the mouth as it rises from the lungs. The airflow is bumped, pinched, or completely blocked. In general, a word contains at least one consonant, and some other words contain more consonants. But a word doesn't have to have any consonants at all, only vowels. Vowels are sounds where the air flows out of the mouth very smoothly because nothing is 
blocking or blocking it. It can be said that vowels are the heart or essence of words and syllables (Yoshida, n.d.).

English syllable according to (Aslam \& Amin Kak, 2011) can be defined as a group of one or more sounds. An important part of a syllable is a vowel sound which can be preceded or followed by a consonant or a group of consonants. Some syllables consist of only one vowel sound. In English, a syllable can consist of vowels starting with one consonant or more. There are types of syllables, for example, weak syllable and strong syllable. Weak syllables can be said that the syllable is shorter, the intensity is lower and the quality is different than other syllables in a word or sentence, in words that have more than one syllable, there is only one syllable that is more prominent, whether strong syllables are usually ended with coda, while the weak syllable has no coda and ends with one of the shorter vowels.

\subsection{Blindness and Second Language Acquisition}

A literature review on teaching English as a second language (ESL) for blind students (Lintangsari \& Emaliana, 2020) reveals scarcity of material in the field of vision education and applied linguistics (Milian \& Pearson, 2005). Blindness affects the development of children with visual disabilities from birth in different ways, language development being one area who are less affected by a lack of vision.

The teaching process of students with visual disabilities in an inclusive classroom requires a variety of teaching methods. Taking into account learning preferences and learning styles also affects student academic achievement. Students with visual disabilities requires various opportunities to explore and study learning material through alternative senses other than visual input for example tactile and audio input (Lintangsari \& Emaliana, 2020).

The first language is acquired from childhood, but the second language is acquired after a certain age, this occurs at the general age of 12 years and can be learned through a combination of conscious and unconscious strategies. In the teaching and learning process of ESL, training is needed to provide visionary teachers with texts that are in accordance with the language that is below the current level of student understanding, collaboration between visionary teachers and ESL teachers must be a fundamental component of learning activities for visually impaired students.

\section{Method}

\subsection{Ethical Clearance}

Respecting the rights of the participants, the researchers ensuring the ethical clearance and participants concerns. This research has gone through ethical clearance by Center for Disability Studies and Services, Universitas Brawijaya under the number of 153/UN10.C20.11/PN/2020. All participants were asked their concern for their 
participation in this research, proper accommodation has been provided and participants' safety and comfort has been well facilitated.

\subsection{Research Participant}

7 students with visual disabilities who are attending Higher Education participated in this research. All of them are learning English as a Foreign Language and have been frequently exposed to English both passively and actively. 5 participants are totally blind while 2 others are having low vision.

Table 1 illustrate the demographic of the participants. This research invited 7 students with visual disabilities that consist of 2 females and 5 males. All of the participants are braille users but only 2 of 7 participants are active braille users and the other participants stated that they rarely use braille so 5 of participants are passive braille users. The participants have been learning English in the span of 10 to 13 years as a passive English speaker.

Table 1. Participants Demographic

\begin{tabular}{|l|l|l|l|}
\hline Initial & Gender & $\begin{array}{l}\text { University } \\
\text { /School }\end{array}$ & $\begin{array}{l}\text { Kind of } \\
\text { blindness }\end{array}$ \\
\hline R1 & Male & Brawijaya University & Low Vision \\
\hline R2 & Male & State University of Malang & Low Vision \\
\hline R3 & Male & Brawijaya University & Totally Blind \\
\hline R4 & Male & Brawijaya University & Totally Blind \\
\hline R5 & Male & UIN Sunan Kalijaga Yogyakarta & Totally Blind \\
\hline R6 & Female & Inklusif Sema Islam Walisongo & Totally Blind \\
\hline R7 & Female & SLBN Pembina Malang & Totally Blind \\
\hline
\end{tabular}

\subsection{Research Instrument}

This research employed an English Phonology Battery adapted from Michael Heggerty's instrument (2017) and Shepthia's instruments (2018). It consists of 6 sections, they are Syllable deletion tasks, Phoneme deletion tasks, English Word reading test, Phoneme in Isolation (Onset Fluency, Medial sounds and Final Sounds), Phoneme Blending and Phoneme Segmentation.

Syllable deletion is the ability to mention one of many syllables that is left after the other syllable is deleted in a word. Syllable deletion tasks (syllable awareness) aim is to measure how aware the student with visual disabilities is to the remaining syllables in a word that some syllables are deleted. In this test there are 5 items for example ('dəon^t) then the syllable nut is removed so that it remains the syllable do-. 
Phoneme deletion Task is the ability to identify one of the phonemes in words. For example, on the word /fæt/, phoneme /æt/ is eliminated so only the sound /f/ remains.

English Word Reading test is the ability to identify the structure of the word so the participant has to identify the consonant and vowel of words. For example, in the word /fæn/, the participants break down the word in a group of sound, sounds / $f$ / as consonants, /æ/ as vowels and /n/ as consonants.

Identifying Phoneme in isolation consist of 3 measures, onset fluency or initial sounds, medial sounds and final sounds. Initial sound awareness is the ability to identify the initial sounds in an English word. Final sound awareness is the ability to identify the final sounds in an English words and medial sound awareness is the ability to identify the medial (middle) sounds in words. The example of initial sound is /mæd/ has the beginning sound $/ \mathrm{m} /$, the final sound of $/ \mathrm{k} \wedge \mathrm{p} /$ is $/ \mathrm{p} /$ and the middle sound of / get/ is $/ \varepsilon /$.

Phoneme Blending is the ability to blend the phoneme in words. This task aim is to measure how aware the student with visual disabilities is in blending phonemes. The example of Phoneme Bending task is the sounds / $f-r-\partial-\mho-z /$ should be blended become froze.

Phoneme Segmentation is the ability to segment the word in phoneme. Segmenting words into phonemes is the ability to divide the words into phonemes. This task aim is to measure how aware the student is with visual disabilities to segmenting one by one of sound from a word. The example of segmenting word into phoneme is the word fun is segmented become $/ \mathrm{f}-\Lambda-\mathrm{n} /$.

\subsection{Procedure}

\subsubsection{Try Out}

Due to Covid 19 pandemic, the data collection should be done online. To minimize the technical issue, a tryout has been done. 1 participant with total visual loss participated in the try out which was conducted on line. During the try out, some beneficial feedbacks related to data collection instruction and technical procedures was evaluated. Based on the try out, the researcher found out that some connection issues were commonly found when we used a conference call, therefore, the researchers utilized the Voice Note features in WhatsApp to send the instruments and receive the participants' response.

\subsubsection{Data Collection}

All participants were individually tested online. In data collection of syllables deletion, the participants were given audio containing a word, then the participants were asked to mention other syllables after some of them have been removed through voice notes. Then, followed by Phoneme deletion, the participants were given audio 
containing a word, then the participants were asked to mention one sound after some of them have been removed through voice notes.

In data collection of identification skill on isolated phonemes that consist of initial sound, final sound, and middle sound the participants were given audio containing one word, then the participants were asked to mention the beginning, the final sound and the middle sounds of the word through voice notes. To collect the data of English Word Reading Test, the participants were given audio containing one word, then the participants were asked to break down the word in a group of sound.

In data collection of phoneme blending, the participants were given audio containing several sounds, then the participants were asked to blend that several sound in order to make the sounds become a word through voice notes.

In data collection of phonemes segmentation skills, the participants were given audio containing a word, then the participants were asked to divide or separate the sounds of the word into several sounds through voice notes.

\subsubsection{Data Analysis}

The researcher examined the data from the Phonemic Awareness Test that students have already done before. Each correct answer gets 1 score. The total score of each skill is 10. Then the total score for all skills is 90 . The data is rated by two raters in order to maintain the objectivity. The next step is measuring the average score to see the amount of variation in the collected data.

The collected data is analyzed descriptively. The analysis of the result of the phonemic awareness test is divided into two. First is the average score of 8 skills in the Phonemic awareness test to know the participants awareness of English Phonemes and second is the most incorrect answers that the students often make on each skill.

\subsubsection{Scoring Agreement}

To ensure the consistency of two raters, interrater agreement was applied. Cohen kappa statistical analysis using SPSS was implemented. The concurrence amid the raters can be utilized as an indicator of the excellence of the categories of the rating instrument and the raters' capability to apply them. High concurrence between the ratings shows agreement in the analysis and interchangeability of the ratings. Cohen's kappa is the most commonly used statistic for evaluating nominal concurrence between two raters [1-7]. Kappa has a value of 1 if there is perfect concurrence between the raters, and a value if the observed agreement is equal to agreement expected by chance. Some authors have recommended analysis or benchmark rules for values between and 1. The most commonly used rules are due to Landis and Koch [8]: $0.00-0.20$ shows slight agreement, 0.21-0.40 fair agreements, 0.41-0.60 moderate agreement, 0.61- 0.80 substantial agreement, and 0.81-1.00 shows almost perfect agreement. (Warrens, 2015). 


\begin{tabular}{|c|c|c|c|c|c|}
\hline \multicolumn{6}{|c|}{ Symmetric Measures } \\
\hline & & Value & $\begin{array}{c}\text { Asymptotic } \\
\text { Standard Error }\end{array}$ & Approximate $\mathrm{T}^{\mathrm{b}}$ & $\begin{array}{l}\text { Approximate } \\
\text { Significance }\end{array}$ \\
\hline \begin{tabular}{|l|} 
Measure of \\
Agreement
\end{tabular} & Kappa & .418 & .169 & 3.186 & .001 \\
\hline \multicolumn{2}{|c|}{ N of Valid Cases } & 8 & & & \\
\hline
\end{tabular}

Table 2. Interrater Agreement

Based on the result of Cohen's Kappa testing, the scoring which was done by two raters showed moderate agreement with Kappa value 0.418 as seen in table.

\section{Finding and Discussion}

\subsection{Finding}

This part elaborated the findings based on the dimensions of the Phonological Awareness test that consists of Phoneme in Isolation, Blending and Segmenting, Syllable Deletion, English Word Reading test, phonemes blending and phonemes segmentation.

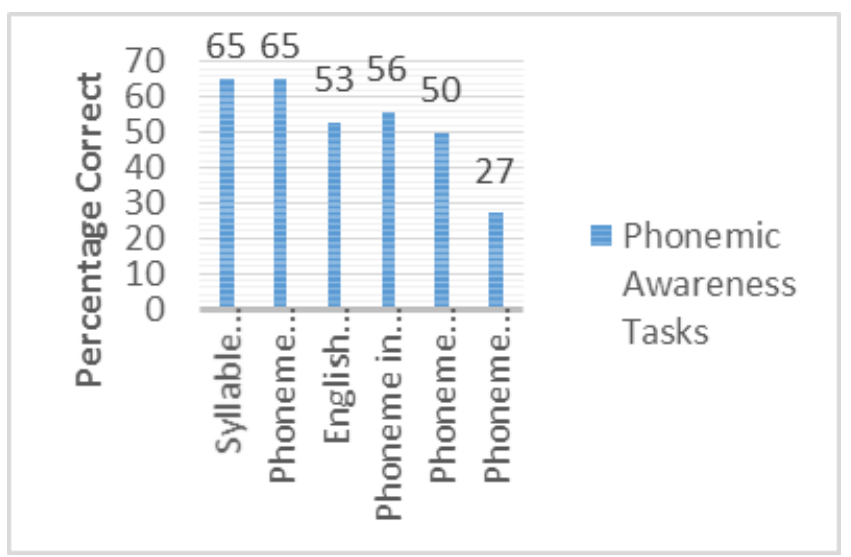

Figure 1. Phonemic Awareness Tasks

The result is presented in a percentage of correct score for analysis. Figure 1 illustrated the result of the phonological awareness test of blind students. Among 6 tests, the participants are apparently more struggling in phoneme level rather than syllable level. As the figure shows that the blind students performed better on syllable level test such as syllable deletion task (65\% correct) and English word reading test (53\% correct). Whereas, they performed a slightly lower score on phonemic level as the data shows that $27 \%$ correct in phoneme segmentation, $50 \%$ correct in phoneme blending and $56 \%$ correct in phoneme isolation. Interestingly, despite the lower score in all phonemic level tests, the blind students performed better in phoneme deletion tasks.

\section{English Phonemic Awareness Task}

This section explains the research findings obtained from the Phonemic Awareness Test. The findings of this study focus on how aware the students in English phonology measured in syllabic and phonemic level. The test consists of Syllable 
deletion, Phoneme Deletion, English Word Reading Test, Identifying the Beginning Sound, Identifying Final Sound, Identifying Middle Sound, Blending phonemes into words, and Segmenting Words into Phonemes.

\section{Syllable Deletion}

Syllable deletion is the ability to mention one of many syllables that left after the other syllable are deleted in a word. Figure 2 shows the details results of blind students' awareness on English syllable. Based on the findings, all the participants have correctly aware on CV (Consonant-Vowel) English construction as in the sounds /do-/ and CCVC English construction as in the sound $/ \mathrm{krēm} /$. Then there are 6 out of 7 participants that correctly aware on CVC English construction as in the sound/fut/, CVVC English construction as in the sound/parn/ and CVVC English construction as in the sound /bark/.

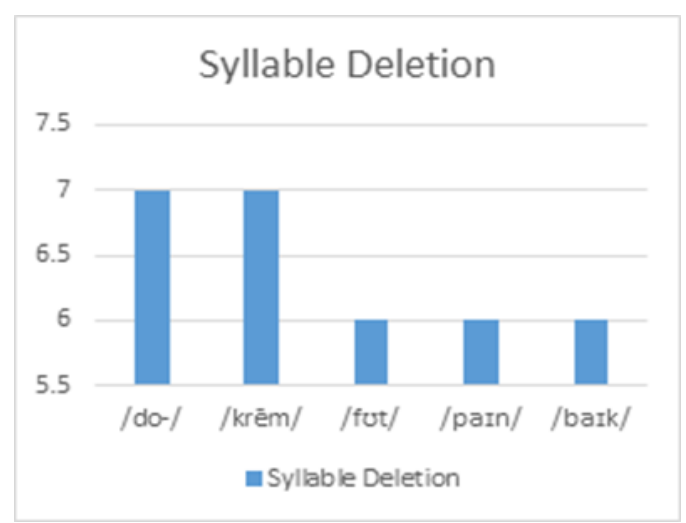

Figure 2. Syllable Deletion

\section{Phoneme Deletion}

Phoneme Deletion task is the task that requires participant to answer what phoneme remains in one word when some phoneme has been deleted.

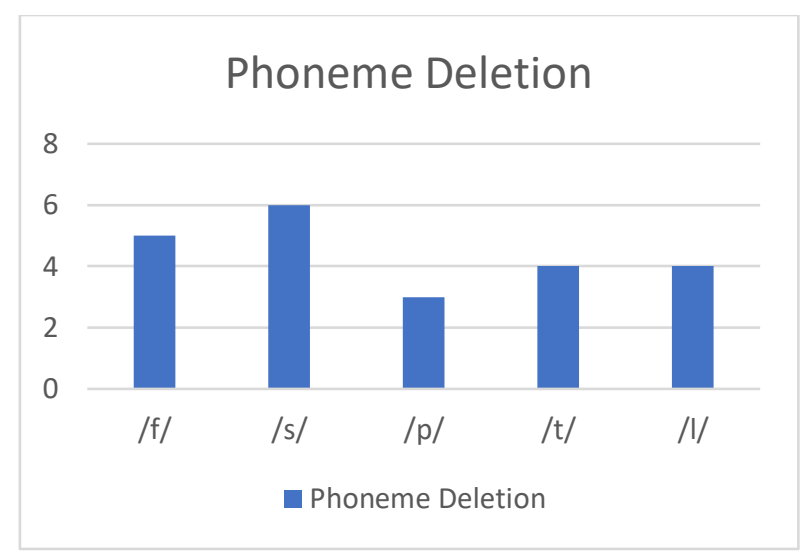

Figure 3. Phoneme Deletion

Figure 3 explicate the performance of the blind students in assessing phoneme deletion tasks. Among 5 consonants being tested, the blind students performed best on consonant /s/ (fricative alveolar sound) as 6 of 7 participants has answered correctly, followed by /f/ sound (fricative labiodental sound) as 5 of 7 participants has answered 
correctly. 4 of 7 students has correctly answer /t/ (plosive-alveolar sound) and /// (lateral approximant alveolar sound) and 3 students has correctly answered /p/ (plosive bilabial sound).

\section{English Word Reading Test}

English Word Reading test is the ability to identify the structure of the word so the participant has to identify the consonant and vowel of words.

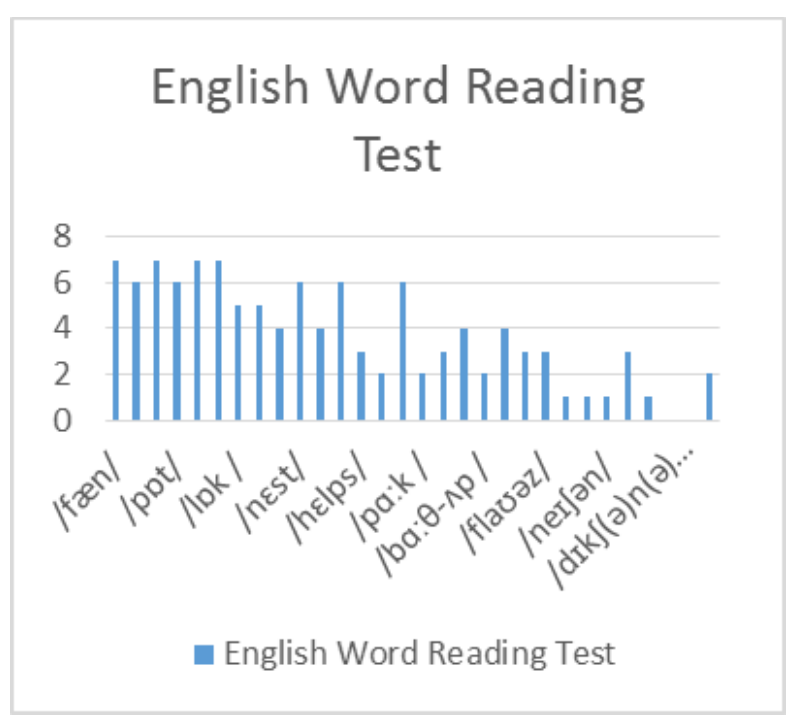

Figure 4. English Word Reading Test

Figure 4 shows that, all the participants have correctly aware on CVC English construction as in the sounds /fæn/, CVC English construction as in the sounds /pig/, CVC English construction as in the sounds / kæt/ and CVC English construction as in the sounds / kId/. Then followed by CVC English construction as in the sounds /dzet/, CVC English construction as in the sounds/ppt/, CVCC English construction as in the sounds /nest/, CVCC English construction as in the sounds /d $\wedge \mathrm{ks} /$ and CVC English construction as in the sounds /mu:n/ there are 6 participants out of 7 having the correct answer. Next is CVC English construction as in the sounds /lok/ and CVCC English construction as in the sounds /melt/ there are 5 participants who answer correctly and CVCC English construction as in the sounds /gfft /, CVC English construction as in the sounds / $\mathrm{km} /$, CV.CVC English construction as in the sounds/ræbrt/, and CV.CVC English construction as in the sounds /b^kIt/ there are 4 out of 7 participants who answer correctly. Next is CVCCC English construction as in the sounds /helps/, CCVCC English construction as in the sounds /sps:t/, CVC.CVCC English construction as in the sounds/dentist/, CCV.CVCC English construction as in the sounds /flavəz/ and VC.CVC English construction as in the sounds /æktıv/ there are 3 out of 7 participants answer correctly. Next, CCVC English construction as in the sounds /blink/, CVC English construction as in the sounds/pa:k/, CV.CVC English construction as in the sounds /ba: $\theta-\wedge p /$, and CCV.CV.CVC English construction as in the sounds /blu:bəriz/ there are 2 out of 7 participants who answer correctly. Then, CVC.CVV English construction as in the sounds/s^ndei/, CV.CVC.CCVV English construction as in the sounds /b^təflai/, CV.CVC English construction as in the 
sounds /neIfən/, and CVV.CVC English construction as in the sounds /serlə/ only 1 out of 7 participant answer correctly. Last is all participants are struggling in identifying the CVC.CV.CV.CV English construction as in the sounds/dictionary/ and CVC.CCV.CVC English construction as in the sounds/conclusion/.

\section{Identifying The Beginning Sound}

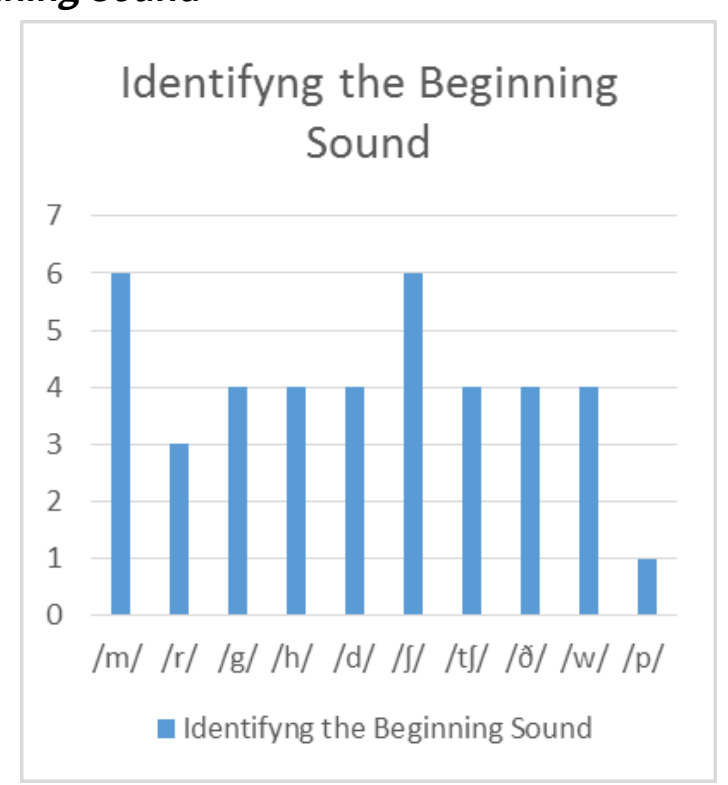

Figure 5. Identifying the Beginning Sound

Initial word awareness is the ability to identify the initial sounds in words. The figure above shows that in identifying initial sound / $\mathrm{m} /$ (plosive bilabial sound), and / $\mathrm{J} /$ (fricative alveolar sound), there are 6 out of 7 participants that answer correctly. Then followed by initial sound /g/ (plosive velar sound), /h/ (fricative velar sound), /d/ (plosive alveolar sound), /t (affricative alveolar sound), /ð/ (plosive alveolar sound), and /w/ (fricative bilabial sound) there are 4 participants out of 7 having the correct answer. Next is the initial sound / $r$ / (retroflex alveolar sound) there are 3 participants who answer correctly and the initial sound /p/ (plosive bilabial sound) there are only 1 participant who answers correctly.

Identifying Final Sound 


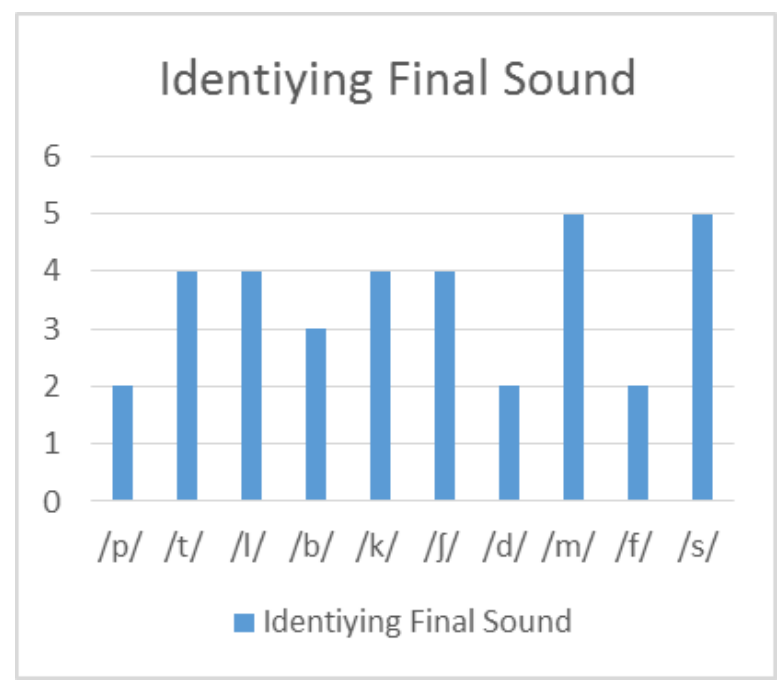

Figure 6. Identifying Final Sound

The figure above shows that in final sound / $\mathrm{m} /$ (plosive bilabial sound), and /s/ (fricative alveolar sound) there are 5 out of 7 participants with the correct answer. Then followed by final sound /k/ (plosive velar sound), /t/ (plosive alveolar), /l/ (lateral approximant alveolar sound), and /J/ (fricative alveolar sound), that there are 4 participants out of 7 having the correct answer. Next is the final sound /b/ (plosive bilabial sound) there are 3 out of 7 participants who have the correct answer. In the final sound /p/ (plosive bilabial sound), /d/ (plosive alveolar sound) and /f/ (fricative labiodental sound) there are 2 out of 7 participants who answer correctly.

\section{Identifying Medial Sound}

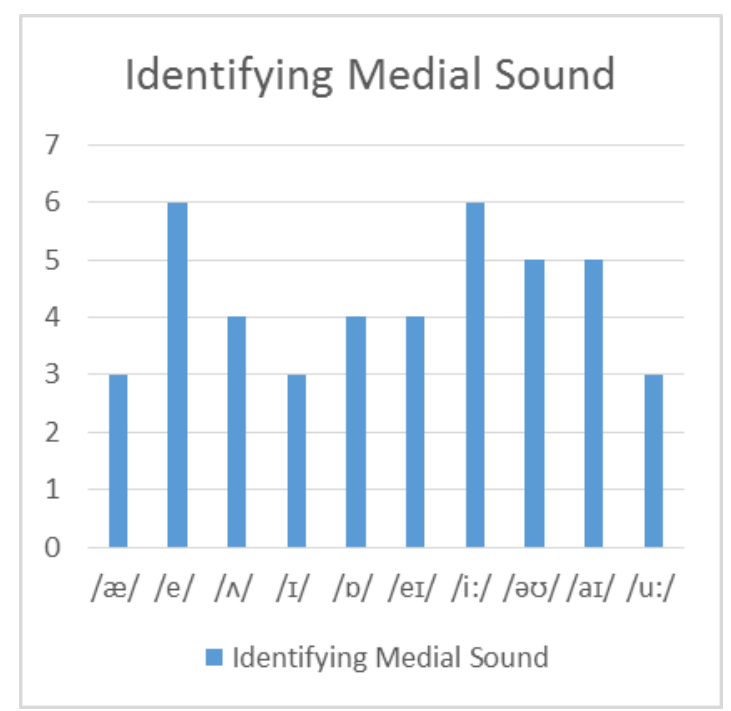

Figure 7. Identifying Medial Sound

Medial sound is the ability to mention the middle sound of a word. Figure 7 shows that in medial sound /e/ (close mid front vowel) and /i:/ (close front long vowel) there are 6 out of 7 participants with the correct answer. Then followed by medial sound /əv/ (close-mid back vowel) and /aI/ (open central vowel) there are 5 out of 7 participants having the correct answer. Next is the medial sound / $\mathrm{p} /$ (open back vowel), /ei/ (close-mid central vowel), and $/ \Lambda /$ (open-mid back vowel), there are 4 out of 7 
participants who have the correct answer. Last, in the medial sound /æ/ (open-mid central vowel), /I/ (close front vowel) and /u:/ (close back long vowel) there are 3 out of 7 participants who answer correctly.

\section{Blending Phonemes into Words}

Blending skill is the ability to combine sounds into words. In taking the data, the participants were given an audio containing several sounds and then the participants were asked to combine several sounds into one word.

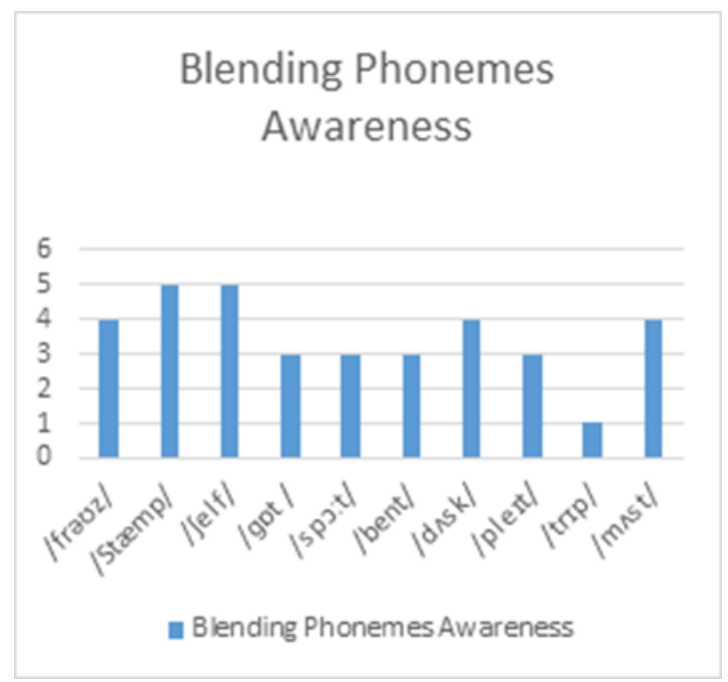

Figure 8. Blending Phoneme Awareness

Figure 8 shows that in the participant are aware on CCVCC English construction as in the sounds /stæmp/ and CVC English construction as in the sounds/Jelf/, there are 5 out of 7 students with the correct answer. Then followed by CCVC English construction as in the sounds /frovz/, CVCC English construction as in the sounds/d $\wedge \mathrm{sk} /$, and CVCC English construction as in the sounds $/ \mathrm{m} \wedge \mathrm{st} /$ there are 4 students out of 7 having the correct answer. Next is CVC English construction as in the sounds/gnt/, CCVC English construction as in the sounds /spo:t/, CVCC English construction as in the sounds /bent/, and CCVVC English construction as in the sounds/pleit/, there are 3 out of 7 students who have the correct answer. The last is CCVC English construction as in the sounds /trip/, only 1 out of 7 students who answer correctly.

\section{Segmenting Words into Phonemes}

Segmenting words is dissecting the word according to the existing sound structure so that the participant mentions the sound arrangement contained in the word being tested through voice notes. 


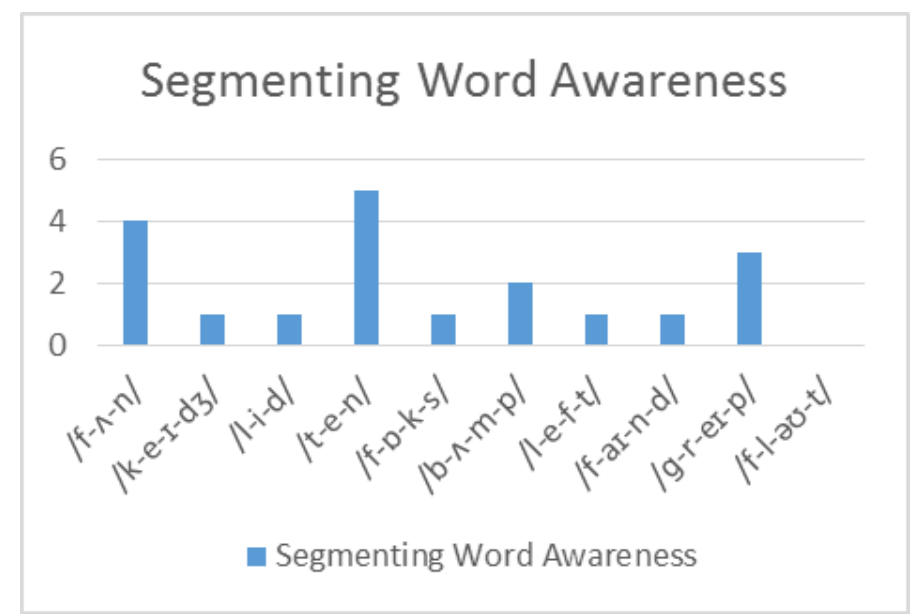

Figure 9. Segmenting Word into Phoneme

Figure 9 shows that participant aware in CVC English construction as in the phoneme $/ \mathrm{t} / \mathrm{e} / / \mathrm{n} /$, there are 5 out of 7 participants with the correct answer. Then followed by CVC English construction as in the phoneme $/ \mathrm{f} / / \mathrm{\Lambda} / \mathrm{n} /$, that there are 4 participants out of 7 having correct answer. Next is CCVC English construction as in the phoneme $/ \mathrm{g} / / \mathrm{r} / / \mathrm{er} / / \mathrm{p} /$, there are 3 out of 7 participants who have correct answer. Next is CVCC English construction as in the phoneme $/ \mathrm{b} / / \mathrm{N} / / \mathrm{m} / / \mathrm{p} /$, there are 2 out of 7 participants who have correct answer. Last, CVVVC English construction as in the phoneme $/ \mathrm{k} / / / \mathrm{e} / / \mathrm{I} / / \mathrm{d} 3 /$, CVC English construction as in the phoneme $/ \mathrm{l} / / \mathrm{i} / / \mathrm{d} /$, CVCC English construction as in the phoneme $/ \mathrm{f} / / \mathrm{p} / / \mathrm{k} / / \mathrm{s} /$, CVCC English construction as in the phoneme $/ \mathrm{l} / \mathrm{e} / / \mathrm{f} / / \mathrm{t} /$, and CVCC English construction as in the phoneme $/ \mathrm{f} / / \mathrm{ar} / / \mathrm{n} / / \mathrm{d} /$ only 1 out of 7 participants who answer correctly.

\subsection{Discussion}

Having the ability to segment or decode words into their smallest amount of fraction can develop awareness and perceptive words that have distinct meanings. (Zhao et al., 2017) stated that the role of metalinguistic awareness and phonological awareness is crucial as one of its subsets in acquiring English Spelling both for native speakers and foreign speaker in English. Various research explicates that pronunciation slip or error is measured as normal for English speakers in Indonesia, and most of them are due to the negative transfer of their mother tongue, Bahasa Indonesia towards English (Gozali, 2019). In the process of English language acquisition, it is apparently influenced by the first language phoneme factor.

Related to the blind students' cases, it is presumed that the factor might not only triggered by the first language phoneme segments but also their disability that affect the visual input. Table 10 shows the patterns of blind students' English phonological awareness from the most to the least performance. 
Table 3. Summary of Blind Students English Phonological Awareness

\begin{tabular}{|c|c|c|c|c|c|c|c|}
\hline \multicolumn{3}{|c|}{$\begin{array}{c}\text { Syllable Construction } \\
\text { Total Task: } 186\end{array}$} & \multicolumn{3}{|c|}{$\begin{array}{c}\text { Consonant } \\
\text { Total Task: } 82\end{array}$} & \multicolumn{2}{|l|}{$\begin{array}{c}\text { Vowels } \\
\text { Total Task: } 43\end{array}$} \\
\hline Pattern & $\mathbf{N}$ & $\%$ & Type of Consonant & & & Type of Vowels & \\
\hline CV & 7 & 100 & $\begin{array}{l}\text { Fricative alveolar } \\
(/ \mathrm{s} / \text { and } / \mathrm{J} /)\end{array}$ & 1 & 5 & $\begin{array}{l}\text { Close mid front vowel } \\
\text { (/e/) and Close front long } \\
\text { vowel (/i:/) }\end{array}$ & 5.7 \\
\hline CVC & 75 & 71.4 & $\begin{array}{l}\text { Plosive bilabial (/p/ } \\
, / \mathrm{m} /, / \mathrm{p} / \text { and } / \mathrm{b} /) \\
20 \text { of } 42 \text { correct } \\
(47,6 \%)\end{array}$ & 0 & 7,6 & $\begin{array}{l}\text { Close-mid back vowel } \\
(/ \partial \mho /) \text { and Open central } \\
\text { vowel (/ar/) } 5 \text { of } 7 \text { correct } \\
(71,4 \%)\end{array}$ & 1,4 \\
\hline CVCC & 36 & 46,7 & $\begin{array}{l}\text { Plosive alveolar } \\
(/ \mathrm{d} /, / \mathrm{t} / \text { and } / ð /) 14 \\
\text { of } \quad 28 \text { correct } \\
(71,4 \%)\end{array}$ & 4 & 0 & $\begin{array}{l}\text { Open back vowel }(/ \mathrm{p} /) \text {, } \\
\text { Close-mid central vowel } \\
\text { (/eI/), and Open-mid back } \\
\text { vowel }(/ \Lambda /) 4 \text { of } 7 \text { correct } \\
(57,1 \%)\end{array}$ & 7,1 \\
\hline CCVC & 20 & 47,6 & $\begin{array}{l}\text { Plosive velar }(/ \mathrm{g} / \\
\text { and } / \mathrm{k} /) \quad 8 \text { of } 14 \\
\text { correct }(57,1 \%)\end{array}$ & & 7,1 & $\begin{array}{l}\text { Open-mid central vowel } \\
(/ æ /) \text {, Close front vowel } \\
(/ \mathrm{I} /) \text { and Close back long } \\
\text { vowel }(/ \mathrm{u}: /) 3 \text { of } 7 \text { correct } \\
(42,9 \%)\end{array}$ & 2,9 \\
\hline CVVC & 12 & 85,7 & $\begin{array}{l}\text { Fricative } \\
\text { labiodental (/f/) and } \\
\text { Lateral } \\
\text { approximant } \\
\text { alveolar (/l/) } 7 \text { of } 14 \\
\text { correct }(50 \%)\end{array}$ & & 0 & & \\
\hline CV.CVC & 11 & 39,2 & $\begin{array}{l}\text { Fricative velar }(/ \mathrm{h} /) \\
\text { and Affricative velar } \\
(/ \mathrm{t} /) 4 \text { of } 7 \text { correct } \\
(57,1 \%)\end{array}$ & & 7,1 & & \\
\hline CCVCC & 5 & 71,4 & & & & & \\
\hline $\begin{array}{l}\text { CVCCC, CCVVC, } \\
\text { VC.CVC, } \\
\text { CCV.CVCC and } \\
\text { CVC.CVCC }\end{array}$ & 3 & 42,8 & & & & & \\
\hline CCV.CV.CVC & 2 & 28,6 & & & & & \\
\hline $\begin{array}{l}\text { CVV.CVC, } \\
\text { CVC.CVV and } \\
\text { CV.CVC.CCVV }\end{array}$ & 1 & 14,3 & & & & & \\
\hline
\end{tabular}

Phonetic awareness demonstrates the skills of EFL learners to recognize English consonants in the focus and way of articulation, English vowels in tongue height, tongue position, and lip adjustment, diphthongs and triphthongs in English words, explicit cases of English consonants and vowels. (Hismanoglu, 2012). Based on the figure above 
student with visual disabilities are very aware in identifying the syllable construction CV, CVC and CVCC. Then, student with visual disabilities also aware in identifying the syllable construction CCVC and CVVC. Next, student with visual disabilities is quite aware with the syllable construction CV.CVC and CCVCC. They are struggling in identifying syllable construction CVCCC, CCVVC, VC.CVC, CCV.CVCC, CVC.CVCC, CCV.CV.CVC, CVV.CVC, CVC.CVV and CV.CVC.CCVV. These basic speech sounds are the phonemes of the language (He \& Wang, 2009). Phoneme can be found by seeing its unique symbol inside slant bracket /"/, which is the standard of identifying phoneme. In identifying consonant, student with visual disabilities have good awareness on Fricative alveolar (/s/ and / //), Plosive bilabial (/p/, /m/, /p/ and /b/), and Plosive alveolar(/d/ and /ð/). Then, they are quite aware on Plosive velar $(/ \mathrm{g} /$ and $/ \mathrm{k} /$ ) and Fricative labiodental (/f/) and Lateral approximant alveolar (///), but struggling on Fricative velar $(/ \mathrm{h} /)$ and Affricative velar (/t/).In identifying vowel or medial sound, they are aware with Close-mid front vowel (/e/) and Close front long vowel sounds (/i:/), Close mid back vowel (/əv/) and Open central vowel (/ar/) but struggling in identifying Open back vowel (/p/), Close mid central vowel (/ei/), and Open mid back vowel $(/ \Lambda /)$. From these results, it can be seen that students' phonemes in identifying abilities are still not good, instead onset and rhyme are the most effective focus for phonological activities to encourage reading and spelling for all children (Monson \& Bowen, n.d.). The use of syllable onset or rhyme difference as the main unit in the initial study of word structures. The use of syllable onset or rhyme difference as the main unit in the initial study of word structures tends to speed up the development of awareness at more difficult phoneme levels. This is due to the fact that students are struggling to accomplish phonemic awareness tests. The results of the study from (Dwi Adeline, 2020) state that the differences of sound systems between their native language and their foreign language are the problems faced by the students.

\section{Conclusion}

English phonemes are challenging for students, especially they are blind students. It contributes to the language acquisition of second language learners, to be specific, the awareness of English Phonemic will influence students' English acquisition.

Based on the test result for the Syllable Deletion Tasks, it can be concluded that the most of students with blindness are aware to identify the syllable /do-/ and / krēm/. Then for Phoneme Deletion Tasks it can be concluded that blind students are struggling in identifying phoneme /p/. Part of the English Word Reading Test can be concluded that blind students are struggling in identifying the beginning sound/dictionary/ and /conclusion/. Identifying Beginning Sound, It can be concluded that blind students are struggling in identifying the beginning sound /p/. Identifying final sound, It can be concluded that blind students are struggling in identifying final sound /p/, /d/, and /f/. Identifying Medial Sound, It can be concluded that blind students are struggling in identifying medial sound /æ/,/I/ and /u:/. Blending Phonemes into Words It can be concluded that blind students are struggling in blending phonemes into word /trip/. 
Segmenting Words into Phonemes, It can be concluded that most of the blind students are struggling in segmenting word into phoneme /f//l//əv//t/.

Blind student has difficulty that should be understood in decoding a phoneme in a word, the results of this study is related to the previous study conducted by (Gillon \& Young, n.d.) Consideration of possible causes that can limit children's mastery of braille literacy and effectively determine this problem should be of major concern to professionals working with children with visual impairments. The findings of this study suggest that the problems experienced by some blind children who have mastered braille literacy may not simply qualify for the loss of a child's senses or their learning environment. Therefore, awareness of the specific English phonemes is fundamental for English Foreign Language learners as they most likely contribute to word processing skills. By knowing this, the relationship between English phoneme identification skills and word processing skills can be expected as a benchmark for measuring the level of word processing skills. In conclusion, that awareness to recognize phonemes contributes to word processing skills has an impact on students with visual disabilities in understanding and producing words.

\section{Bibliography}

Aslam, M., \& Amin Kak, A. (2011). Introduction to English Phonetics and Phonology. Foundation Books.https://doi.org/10.1017/UP09788175968653

Collins, B., Mees, I., \& Carley, P. (2019). World Accent Varieties 3: Second-Language Varieties and Creole-Influenced Speech (pp. 249-254). https://doi.org/10.4324/9780429490392-22

Dodd, B., \& Conn, L. (2000). The effect of Braille orthography on blind children's phonological awareness. Journal of Research in Reading, 23(1), 1-11. https://doi.org/10.1111/1467-9817.00098

Dwi Adeline, F. (2020). Pronunciation Problems of Indonesian EFL Learners in Pronouncing /g/ Sound. Education of English as Foreign Language, 3(1), 1-16. https://doi.org/10.21776/ub.educafl.2020.003.01.1

Gillon, G. T., \& Young, A. A. (n.d.). The Phonological-Awareness Skills of Children who are Blind. 12.

Gozali, I. (2019). Developing Phonics Material to Improve the Spoken English of Indonesian Tertiary Students. KnE Social Sciences, 3(10), 379. https://doi.org/10.18502/kss.v3i10.3920

He, T., \& Wang, W. (2009). Invented spelling of EFL young beginning writers and its relation with phonological awareness and grapheme-phoneme principles. Journal of Second Language Writing, 18(1), 44-56. https://doi.org/10.1016/j.jslw.2008.06.001

Hill, E., Long, R., Douglas, G., Tobin, M., \& Grimley, M. (n.d.). NEALE ANALYSIS OF READING ABILITY FOR READERS WITH LOW VISION. 35. 
Hismanoglu, M. (2012). An investigation of phonological awareness of prospective EFL teachers. Procedia - Social and Behavioral Sciences, 31, 639-645. https://doi.org/10.1016/j.sbspro.2011.12.117

Jones, D. M., \& Macken, W. J. (1995). Phonological similarity in the irrelevant speech effect: Within- or between-stream similarity? Journal of Experimental Psychology: Learning, Memory, and Cognition, 21(1), 103-115. https://doi.org/10.1037/02787393.21.1.103

Kuo, L., \& Anderson, R. C. (2006). Morphological Awareness and Learning to Read: A Cross-Language Perspective. Educational Psychologist, 41(3), 161-180. https://doi.org/10.1207/s15326985ep4103_3

Lafrance, A., \& Gottardo, A. (2005). A longitudinal study of phonological processing skills and reading in bilingual children. Applied Psycholinguistics, 26(4), 559-578. https://doi.org/10.1017/S0142716405050307

Lailiyah, N., Iswahyuni, I., \& Lintangsari, A. (2020). English Spelling Errors Committed by the Blind. IJDS Indonesian Journal of Disability Studies, 7(1), 66-71. https://doi.org/10.21776/ub.IJDS.2019.007.01.7

Lintangsari, A. P., \& Emaliana, I. (2020). Inclusive education services for the blind: Values, roles, and challenges of university EFL teachers. International Journal of Evaluation and Research in Education (IJERE), 9(2), 439. https://doi.org/10.11591/ijere.v9i2.20436

Melby-Lervåg, M., Lyster, S.-A. H., \& Hulme, C. (2012). Phonological skills and their role in learning to read: A meta-analytic review. Psychological Bulletin, 138(2), 322-352. https://doi.org/10.1037/a0026744

Milian, M., \& Pearson, V. (2005). Research Reports: Students with Visual Impairments in a Dual-language Program: A Case Study. Journal of Visual Impairment \& Blindness, 99(11), 715-720. https://doi.org/10.1177/0145482X0509901111

Monson, M. R., \& Bowen, S. K. (n.d.). The Development of Phonological Awareness by Braille Users: A Review of the Research. 11.

Mott, M. S., \& Rutherford, A. S. (2012). Technical Examination of a Measure of Phonological Sensitivity. SAGE Open, 2(2), 215824401244558. https://doi.org/10.1177/2158244012445584

Perez, M. (n.d.). Elsevier: Encyclopedia of Language and Linguistics 2nd edition. 12.

Rokhman, M. F., Lintangsari, A. P., \& Perdhani, W. C. (2020). EFL learners' phonemic awareness: A correlation between English phoneme identification skill toward word processing. JEES (Journal of English Educators Society), 5(2), 135-141. https://doi.org/10.21070/jees.v5i2.467

Snyder, T., \& Kesselman, M. (1972). Teaching English as a Second Language to Blind People. Journal of Visual Impairment \& Blindness, 66(6), 161-166. https://doi.org/10.1177/0145482X7206600601

Stahl, S. A., \& Murray, B. A. (n.d.). Defining Phonological Awareness and Its Relationship to Early Reading. 14.

Warrens, M. J. (2015). Five Ways to Look at Cohen's Kappa. 5(4), 4. 
Yoshida, M. (n.d.). Understanding and Teaching the Pronunciation of English. 220.

Zhao, J., Dixon, L. Q., Quiroz, B., \& Chen, S. (2017). The Relationship Between Vocabulary and Word Reading Among Head Start Spanish-English Bilingual Children. Early Childhood Education Journal, 45(1), 27-34. https://doi.org/10.1007/s10643-0150764-8 